\title{
Computation of the Bivariate Normal Integral
}

\author{
By Z. Drezner
}

\begin{abstract}
This paper presents a simple and efficient computation for the bivariate normal integral based on direct computation of the double integral by the Gauss quadrature method.
\end{abstract}

1. Introduction. The probability distribution of the normalized Normal Distribution is: [1]

$$
\begin{aligned}
& \Phi(h, k, \rho)=\operatorname{Pr}\left\{\left(x_{1}<h\right) \cap\left(x_{2}<k\right)\right\} \\
& \Phi(h, k, \rho)=\left(2 \pi \sqrt{1-\rho^{2}}\right)^{-1} \int_{-\infty}^{h} \int_{-\infty}^{k} \exp \left[-\frac{x_{1}^{2}-2 \rho x_{1} x_{2}+x_{2}^{2}}{2\left(1-\rho^{2}\right)}\right] d x_{1} d x_{2} .
\end{aligned}
$$

Substitute:

$$
u_{1}=\frac{h-x_{1}}{\left[2\left(1-\rho^{2}\right)\right]^{1 / 2}} ; \quad u_{2}=\frac{k-x_{2}}{\left[2\left(1-\rho^{2}\right)\right]^{1 / 2}}
$$

Define:

$$
h_{1}=\frac{h}{\left[2\left(1-\rho^{2}\right)\right]^{1 / 2}} ; \quad k_{1}=\frac{k}{\left[2\left(1-\rho^{2}\right)\right]^{1 / 2}}
$$

Then:

$$
\begin{aligned}
\Phi(h, k, \rho)= & \frac{\left(1-\rho^{2}\right)^{1 / 2}}{\pi} \int_{0}^{\infty} \int_{0}^{\infty} \exp \left[-u_{1}^{2}\right] \exp \left[-u_{2}^{2}\right] \\
& \exp \left[h_{1}\left(2 u_{1}-h_{1}\right)+k_{1}\left(2 u_{2}-k_{1}\right)+2 \rho\left(u_{1}-h_{1}\right)\left(u_{2}-k_{1}\right)\right] d u_{1} d u_{2} .
\end{aligned}
$$

By Gauss quadrature [2]:

$$
\Phi(h, k, \rho) \doteq \frac{\left(1-\rho^{2}\right)^{1 / 2}}{\pi} \sum_{i, j=1}^{k} A_{i} A_{j} f\left(x_{i}, x_{j}\right),
$$

where

$$
f(x, y)=\exp \left[h_{1}\left(2 x-h_{1}\right)+k_{1}\left(2 y-k_{1}\right)+2 \rho\left(x-h_{1}\right)\left(y-k_{1}\right)\right] .
$$

The values of $A_{i}, x_{i}$ for $k=2, \ldots, 15$, can be found in [3]. If $h, k, \rho \leqslant 0$, then $0<f(x, y) \leqslant 1$, and the error in (5) is relatively small. We will make use of the following formulae in order to calculate the double integral for $h, k, \rho \leqslant 0$. 
2. The Method. The following formulae can be found in [1]:

$$
\begin{aligned}
& \Phi(h, k, \rho)=\phi(h)+\phi(k)-1+\Phi(-h,-k, \rho), \\
& \Phi(h, k, \rho)=\phi(k)-\Phi(-h, k,-\rho), \\
& \Phi(h, k, \rho)=\phi(h)-\Phi(h,-k,-\rho),
\end{aligned}
$$

where

$$
\phi(h)=\frac{1}{2 \pi} \int_{-\infty}^{h} \exp \left[-\frac{x^{2}}{2}\right] d x .
$$

For $h, k \neq 0$

$$
\Phi(h, k, \rho)=\Phi(h, 0, \rho(h, k))+\Phi(k, 0, \rho(k, h))-\delta_{h k},
$$

where

$$
\rho(h, k)=\frac{(\rho h-k) \operatorname{Sgn}(h)}{\sqrt{h^{2}-2 \rho h k+k^{2}}}, \quad \delta_{h k}=\frac{1+\operatorname{Sgn}(h) \cdot \operatorname{Sgn}(k)}{4}
$$

and

$$
\operatorname{Sgn}(x)=\left\{\begin{aligned}
1, & x \geqslant 0 \\
-1, & x<0
\end{aligned}\right\}
$$

Algorithm. If $h \cdot k \cdot \rho \leqslant 0$, then do one of the following:

(a) If $h \leqslant 0, k \leqslant 0, \rho \leqslant 0$ compute directly.

(b) If $h \leqslant 0, k \geqslant 0, \rho \geqslant 0$ use (9).

(c) If $h \geqslant 0, k \leqslant 0, \rho \geqslant 0$ use (8).

(d) If $h \geqslant 0, k \geqslant 0, \rho \leqslant 0$ use (7).

If $h \cdot k \cdot \rho>0$, use (11). Note that every computation of $\Phi$ will now satisfy $h \cdot k \cdot \rho=0$, (since the new $k$ equals 0 ).

3. Results. An advantage of this method is that for every $\rho$ (even close to 1 ) there is no convergence problem. In Table 1 we present results of the average run time and maximum-error for various values of $k$ in (5).

Low values of the exponent in (6) cause $f(x, y)$ to vanish. To save computational effort, if the exponent is lower than the values in Column 4, Table 1, we assume that $f(x, y)$ is zero. The values in the table have been set such that maximumerror remains the same to two significant digits. In Column 5 we present the reduced run time. In order to compare with existing results [4], [5] we take $k=5$. Note here that in $k=3,4,5$ a further reduction of $0.7 \mathrm{~m}$.s. can be achieved by using the approximation in [6] for the error function instead of using the function erf.

By a regression on Column 3 we can deduce that computations outside the double integration are the same for every $k$ and require approximately $1.6 \mathrm{~m} . \mathrm{s}$., so for $k=5$ and the approximated error function the average computation time is 2.2 m.s. The double integration requires an average $1.3 \mathrm{~m} . \mathrm{s}$. 
TABLE 1. Results

\begin{tabular}{rcccc}
\hline$k$ & $\begin{array}{c}\text { maximum } \\
\text { error }\end{array}$ & $\begin{array}{c}\text { run time } \\
\left(10^{-3} \mathrm{sec}\right)\end{array}$ & $\begin{array}{c}\text { limit of } \\
\text { exponent }\end{array}$ & $\begin{array}{c}\text { reduced } \\
\text { run time }\end{array}$ \\
\hline 3 & $1.1 \times 10^{-4}$ & 3.0 & -8 & 1.8 \\
4 & $8.1 \times 10^{-6}$ & 4.1 & -10 & 2.2 \\
5 & $5.5 \times 10^{-7}$ & 5.5 & -12 & 2.9 \\
6 & $3.8 \times 10^{-8}$ & 7.2 & -15 & 3.6 \\
7 & $3.0 \times 10^{-9}$ & 9.2 & -17 & 4.6 \\
8 & $2.2 \times 10^{-10}$ & 11.5 & -20 & 6.0 \\
9 & $1.5 \times 10^{-11}$ & 14.2 & -22 & 7.5 \\
10 & $1.1 \times 10^{-12}$ & 17.0 & -25 & 9.4 \\
& & & & \\
\hline
\end{tabular}

All time data are based on a CDC/6400.

Faculty of Business

McMaster University

Hamiton, Ontario, Canada

1. NORMAN L. JOHNSON \& SAMUEL KOTZ, Distribution in Statistics: Continuous Multivariate Distributions, Wiley, New York, 1972, pp. 93-96.

2. A. H. STROUD \& D. SECREST, Gaussian Quadrature Formulas, Prentice-Hall, Englewood Cliffs, N. J., 1966.

3. N. M. STEEN, G. O. BYRNE \& E. M. GELBARD, "Gaussian Quadratures," Math. Comp., v. 23, 1969, pp. 661-671.

4. R. R. SOWDEN \& J. R. ASHFORD, "Computation of the bivariate normal integral," Appl. Statist., v. 18, 1969, pp. 169-180.

5. D. E. AMOS, "On computation of the bivariate normal distribution," Math. Comp., v. 23, 1969 , pp. 655-659.

6. Y. L. LUKE, Mathematical Functions and Their Approximations, Academic Press, New York, 1975, pp. 123-124. 